\title{
Research on Underpricing Concept of IPO (Initial Public Offering) in Indian Stock Market
}

\author{
Ajay Yadav, Sweta Goel
}

\begin{abstract}
There are several ways of raising funds from primary market but, IPOs are the widely adopted tool by the companies to raise funds from open market for the initial sale of stock by private company. India being a developing nation and flourishing corporate network is focused on IPO. The motivation behind this examination is to understand the case of underpricing exists to think about whether or not an Indian IPO and the impact of the administrative system on IPO underpricing. In this examination enterprise information is broken down by descriptive and comparative method. Indian market has more underpricing than overpricing.
\end{abstract}

Keywords: IPO, Stock Market, Underpricing, Market Framework, corporate, share capital, equity

\section{INTRODUCTION}

IPO is a crucial step for a company's issuance of initial share capital. A company marks its first ever step into the share market. IPO is a hot talk among Indian market, as constellation of corporate are venturing in this growing nation.

\section{The Term IPO (Initial Public Offering)}

An "initial sale of stock" is an organization's first offer of stock to people in general. This is the reason it is additionally termed as "opening up to the world". At the point when an organization that has already issued, stock issues progressively stock it is known as a "second offering"

Various companies that undertake IPO takes the assistance of investment banking which acts as underwriter to advice firms wisely. This process can be used by small or giant companies for expansion and make their company go public.

\section{The Pricing Process}

The Indian securities market has experienced a several building changes especially after the deregulation of the economy. The dynamic financial condition and the floods of globalization and advancement have contributed generously for the extending, augmenting and widening of the securities showcase. A far reaching bundle of changes was acquainted comprising of measures with change, control and build up the showcase, the most commendable change being the destroying of Controller of Capital Issues (CCI) and the presentation of free evaluating

On this ground another system named as book building was perceived as a strategy for evaluating by Securities and Exchange Board of India on the suggestion of the advisory

Revised Manuscript Received on August 05, 2019.

Ajay Yadav, Ph.D Scholar, ACCF, Amity University (U.P) Noida, Utter Pradesh, India.

Dr. Sweta Goel, Asst. Professor, ACCF, Amity University (U.P) Noida, Utter Pradesh, India. group under the chairmanship of Y.H. Malegam in 1995." the essential market saw a blast both regarding no of issues and the measure of issues under SEBI period in contrast with CCI system.

\section{Fixed price method:}

In this method firm with the consultation of investment bank, fixes the price .This is the price at which investor will subscribe to capital. It is a traditional method of pricing the IPOs.

\section{Book Building Method:}

In this Type of method pricing is done by fixing band instead fixing a price. Book Building is a price discovery component utilized by organizations issuing the securities SEBI characterizes book building as "a procedure embraced by which interest for the securities proposed to be issued by a body corporate is inspired and developed and the cost for such securities is evaluated for the assurance of the quantum of such securities to be issued by methods for a document, circular, notice, memorandum or advertisement or offer report."

The lowest cost in the value band is called 'floor cost' and the highest cost is called 'top cost'. A financial specialist can buy in at a cost anyplace in the value band. A speculator who needs to buy in at any cost can make reference to the 'cut-off cost'.

When the problem stops, a book with a descending order of cost is read. The cut-off cost is the cost to which the entire issue is subscribed. It is the most commonly used technique.

Book Building is fundamentally a price and demand disclosure component. Under this framework during the period for which the book for the IPO is open, offers are gathered from speculators at different costs which are above or equivalent to floor cost. The offer cost is resolved after the offer closing date based on some assessment basis.

\section{Underpricing of IPO}

IPO underpricing, basically, is the contrast between the closing offer price of a stock (through IPO) and the end cost of the equivalent on first exchanging (posting) day if the posting cost is higher. Naturally, it gives a short- term speculation open door for the speculators. Consequently, a gigantic surge of firms towards posting on stock trade and producing assets through IPO is additionally trademarked with a huge line of financial specialists sitting tight for IPO 
allotments, development of administrative structure and development of speculation banking in the area of essential market. These novel attributes have made IPO underpricing a fascinating event to contemplate with regards to finance.

Past examinations additionally demonstrate that speculation saves money with high notoriety will in general undervalue IPOs to a lesser degree as due industriousness by very presumed venture banks reflect less danger of an issue among the financial specialist network. By buying in to an IPO, speculators are taking a wagered on the notoriety of speculation banks that have overseen/co-dealt with the issue and henceforth eager to buy in to the issue at a lesser rebate. A sensible end product to this contention is that if the evaluating of the issue isn't done precisely by a speculation bank, the market may punish them in consequent period, which could then be reflected as far as decrease in the market portion of speculation banks for the period under reference. As needs be, it is consistently in the enthusiasm of venture banks to implement undervaluing harmony to the degree conceivable. Thus, the speculation identifying with IPO mispricing and its effect on venture banks ${ }^{\text {ec }}$ piece of the pie should be tried in the event of India so arrangement changes as for the job of venture banks, assuming any, could be recommended. An endeavor has likewise been additionally been made in this investigation to analyze the connection between mispricing by a speculation bank during a given period what's more, change in its piece of the overall industry in the consequent period.

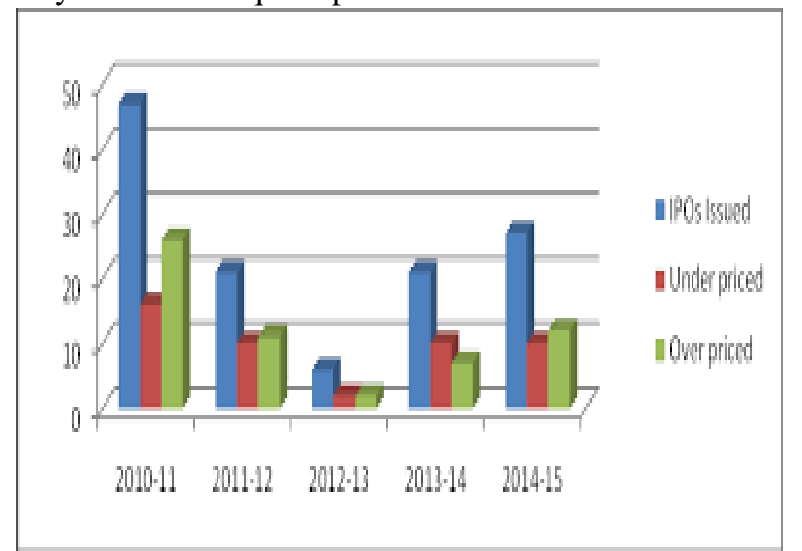

Figure 1.2 Graphical Representation of underpricing, overpricing and IPOs issued from 2010-15

\section{REVIEW OF LITERATURE}

Procianoy and Cigerza (2017) in their near investigation of IPOs in developing markets of Brazil, India and China utilized multivariate direct relapse model with a blend of factors covering IPO explicit data, showcase related elements and full scale parameters. The factors utilized are offer size, Investment bank notoriety, last offer value, showcase execution, sham for products created utilizing cutting edge content, financing cost, FDI, GDP, swelling, and so on. In this investigation, the creators discovered market execution (when the issue) and the innovative sham were the main factors affecting short run beginning come back with satisfactory factual centrality at $12 \%$ or underneath. The autonomous factors utilized in the multivariate investigation of the principal day exchanging execution of the IPOs the Brazilian Market between January, 2014 to April, 2017 by Faria (2017) included age of the firm, proportion of essential offer size to the absolute offer size and nine key proportions: deals, development in deals, dissolvability, liquidity, fixed resource turnover, all out resource turnover, return on equity, return on resources and activity overall revenue. The creator seen that out of all the above free factors, just return on equity was measurably critical with negative connection with undervaluing. While looking at the determinants of introductory IPO execution in Hong Kong and Taiwan, Lin and Hsu (2008), bury alia, found that ,allotment ratio ${ }^{\text {ee }}$ of the bought in offers (all out IPO offers issued over the quantity of offers bought in by the members candidates) was the most reliable determinant for IPO undervaluing in both the Hong Kong just as Taiwanese market.

Dechow et al. (2012) discover exact proof for this "irreconcilable circumstance speculation". Their exploration let them to presume that associated investigators distribute more hopeful figures and stock proposals than unaffiliated examiners. O'Brian et al. (2015) affirm the reluctance of partnered investigators to disperse negative research reports so as to verify speculation banking commands and to limit potential clashes between the business and venture banking divisions and the administration of the customer firm. They moreover see that associated examiners tend to distribute purchase proposals sooner and all the more frequently than unaffiliated experts after an organization has issued securities.

K. Hema Divya (2014) The Analysis from the measurable information that will cover the IPOs of different organizations embracing the book-building course additionally faces underpricing. There is a degree of over membership of an IPO, which will decide the First Day Gains. The over membership will prompt bigger First Day Gains for the IPOs. The examination will assist us with finding out whether the stocks are undervalued or overrated. The small issue-size, independent organizations that will tell the best way to get a handle on the Investors during the blasting IPO showcase and gathered however much cash as could be expected from them. The different class speaks to organizations from Indian business gatherings or Government proprietorship. They undervalued more and returned to speculators after their IPOs to raise more assets, regardless of industry order.

\section{PURPOSE OF STUDY}

- To study the concept of underpricing in IPO's

- To present a comparison of pricing methods of IPO's stock.

- To study the process of pricing of IPO's in primary market.

\section{METHODOLOGY \& RESULTS}

\section{Type of Research}

This study has been done through descriptive method by using various sources of data such as Primary data, Secondary Data. Information Gathered from official

Published By: 
websites such as Bombay Stock Exchange, National Stock Exchange, SEBI etc.

\section{Sample Size}

The sample size for our study is 500 Indian Companies, which issued IPO's during 2010 to 2015.The sample determination is guided by the accessibility of information. The example comprises of 700 fixed value issues and 350 Book Building issues. BSE Sensitive Index is chosen as an agent of the market. BSE is chosen, as it is the biggest stock trade of India. Practically $96 \%$ of the Indian organizations are recorded on BSE. Everyday four estimations of Sensex are accessible viz. opening, high, low and shutting esteem. We have taken rundown esteem also, offer estimation of IPO on various organizations so as to ascertain the underpricing and overpricing.

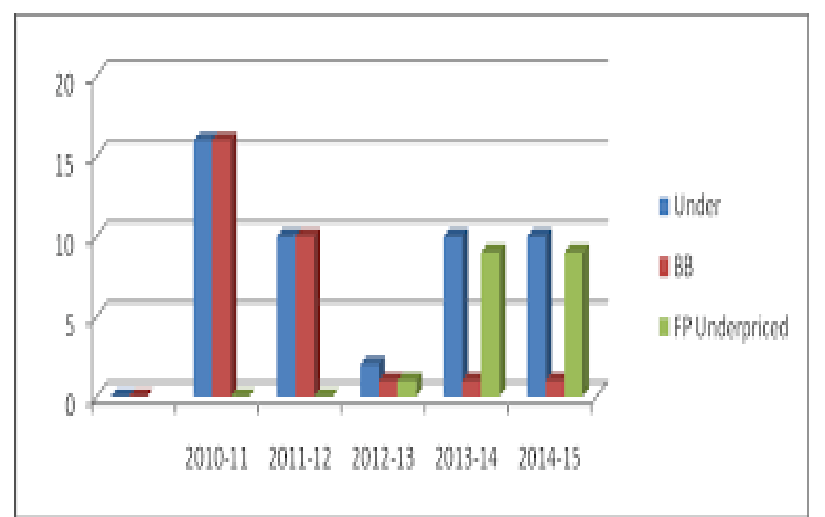

\section{Figure 1.3 Graphical representation of underpriced IPO from 2010-15}

\section{Initial Performance of Price}

It has been pointed out in the empirical literature that most IPOs offer a premium to underlying supporters. IPOs in many countries provide much higher initial returns than various IPOs. furthermore, the references referred to in that). In any case, the accessible observational proof on this issue is for the most part limited to the investigation of created markets and the proof on developing markets is extremely restricted.

Table 1.1 Tabular representation Underpricing and Overpricing Industries

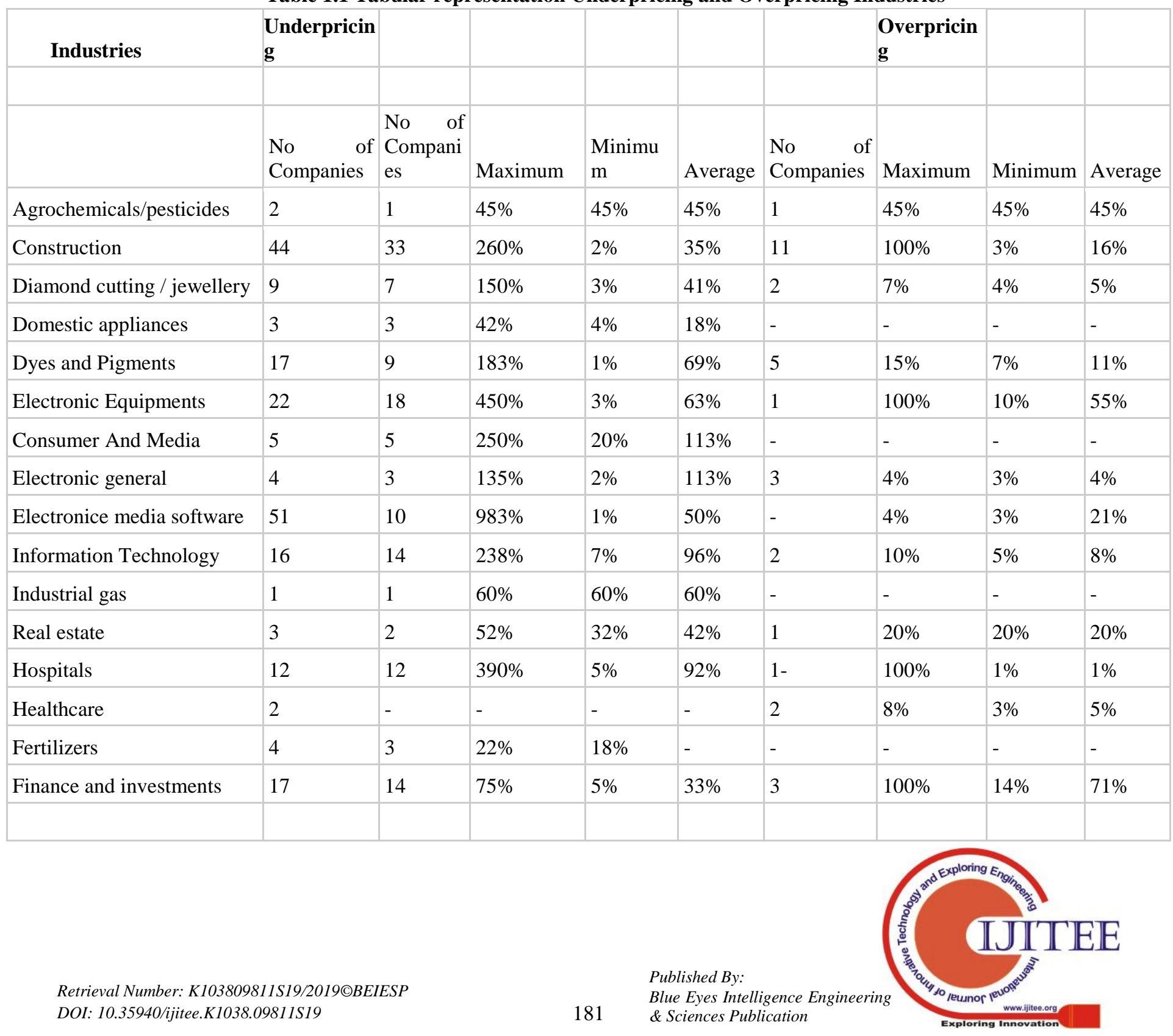


We find that the fixed price pressure for high undervaluing book valuations is followed by a change in the book-building strategy following a change in the administrative system. The book table is decreasing based on strategy. We find that finance and investment IPOs (large / medium / small) are organizations associated with industry underworld and certain organizations. Undervaluing most extreme $75 \%$, least $5 \%$ and the overpricing maximum $100 \%$, least $14 \%$.The IPO of Hospitals is undervaluing and organizations overpricing and the undervaluing is most extreme $390 \%$, least $5 \%$ and the overpricing is maximum $100 \%$, least $1 \%$.

\section{Execution of stock analysts' suggestions}

The financial worth and the valuation impacts of expert suggestions ought to turn out to be particularly apparent when the two limits of the five proposal classifications are examined. In this manner, we center in our investigation on the purchase and sell proposals. To start with, we focus on the transient valuation impacts, i.e., the time-span around the proposal. We discover proof of various securities exchange responses contingent upon the sort of suggestion just as on the gathering of experts that issued this proposal, which implies that there are contrasts in the responses to the suggestions of unaffiliated examiners and the investigators of the co-underwriter and the lead-underwriter.

The total strange returns (CAR) of the purchase proposals plainly uncover that the upward pattern starts even a few days before the declaration date. This outcome is very comparative for the proposals of each of the three gatherings of investigators. Over the multi day occasion period the CARs for every one of the three gatherings is practically indistinguishable. It creates the impression that the market does not separate among partnered and unaffiliated examiners in the valuation of these purchase suggestions.

Interestingly, this isn't the situation for the sell proposals of examiners of the co-underwriter, in light of the fact that they don't have a fundamentally impact on the exhibition during the occasion time frame. Besides, sell proposals for bigger organizations bring about a still negative however generally better transient execution. This features the way that sell suggestions speak to particularly for little organizations a significant negative sign. Part explicit impacts are neither watched for purchase nor for sell proposals around the occasion date. As anyone might expect, the quantity of months that have gone between the IPO and the hour of the sell suggestion assumes a pivotal job. Sell proposals that were issued not long after the IPO are deciphered by the market as a substantially more negative sign than sell proposals that were distributed later on. They additionally bring about a second rate long runexecution. This finding proposes that the capital advertise accurately deciphers the negative sign that is related with a previous sell proposal following the IPO. This end is additionally legitimate for the sell suggestions of the leadunderwriter. After 246 trading days, they have a fundamentally - albeit more fragile - negative effect on the irregular returns.

\section{HYPOTHESIS}

The concerned research studies the process of valuation of IPO in primary market.

The following hypothesis had been drawn from the research.

1. By this research it is prescribed that book building is the most suitable method of evaluating IPO.

2. The examination of the stock proposals bolsters the theory that the investigators of those banks which have went with a firm as lead-underwriter for an IPO, issue increasingly positive proposals.

\section{RECOMMENDATION}

In view of breaking information, we can state that book making is the best strategy for evaluating an IPO in light of the fact that it understands the significant price spread that is found in regularly determined valuation techniques. In book creation techniques, there is less possibility of cost changes.

\section{CONCLUSION}

In India, there is normal $76 \%$ underpricing what's more, normal $44 \%$ overpricing which can be acquired by distinct investigation strategy. It happens on the grounds that undervaluing depends on data creation and possession scattering which will profit the issuing firms. On the off chance that issuing firms need to have an increasingly scattered possession, They have to reduce their IPOs with the goal that more financial experts will be motivated to give data about the problem.

So buy offers. Similarly, media is influenced by thought and risk. The result also recommended that after changing the administrative structure, book production IPOs show lower devaluation than fixed price issues. The normal undervaluing value is met at $102 \%$ of the fixed cost and $25 \%$ by the bookmaking technique that can be achieved by the knowledge check technique. It happens on the grounds that the guarantor sets a value goes inside which the financial specialist is permitted to offer for offers. The range depends on where focused organizations are exchanging and a gauge of the estimation of the organization that the market will bear.

\section{REFERENCES}

1. “Alweraz and Gemalez" (2001), 'SPANISH PUBLIC OFFERING FOR THE PERIOD' 1987-1997'

2. “Agarwal” (2002), 'INITIAL PUBLIC OFFERING, research paper.

3. "Adams Michael, Barrythornto, George Hall" (2008) 'IPO PRICING PHENOMENA: EVIDENCE OF BEHAVIOURAL BASES, Journal of Business and Economics Research, Vol no 6.

4. "Gompers and Lerner" (2001) 'ANALYZED THE PERFORMANCE OF IPOs IN UNITED STATE'.

5. Jingyun Ma, Fengming Song and Zhishu Yang, (2010), "The dual role of the government: securities market regulation in China 1980-2007", Journal of Financial Regulation and Compliance, Vol. 18 Issue: 2, pp.158 177 
6. "K.HemaDivya" (2013) 'A STUDY ON PERFORMANCE OF INDIAN IPO'S DURING THE FINANCIAL YEAR 2010- 2011',International Journal of Marketing, Financial Services \& Management Research, Vol no 7,pp- 1-11

7. Kun Wang, (2008), "Does pre-deal research reduce IPO underpricing”, Pacific Accounting Review, Volume 20, Issue: 3.

8. "Murti Krishna" (2002) "ANALYSES DAMPLE OF IPOS ISSUED DURING THE PERIOD FROM 1988 TO 1994 '. 